\title{
Capture Programmes for Rare Animals
}

When animals are in danger of extinction, capture programmes, either for breeding in captivity or to transfer some to safer areas, may be the best hope of saving the species. The Survival Service Commission of IUCN, in a policy statement, has laid down the conditions that justify such programmes and the rules that should be observed, of which all but the first apply to all captures.

The capture of rare or endangered animals, either for relocation or in order to establish captive breeding units, can be a preliminary step towards the maintenance of viable populations in the wild, says a policy statement issued by the Survival Service Commission of IUCN. Relocation-introducing animals into areas where the species still exists or has occurred in historical times-may strengthen the viability of an existing population, diversify the fauna in the interests of good management or for research, or conserve a population whose existing habitat is threatened. Captive breeding units may be established in sanctuaries within the species' range or in scientifically managed sites, such as zoos or research centres. The aims in both should be to increase numbers, to providing a reservoir of animals for restocking in the wild, and to permit scientific study of the species under controlled conditions.

Six provisions for a capture programme are laid down:

I. Captures for commercial reasons are only justified if they satisfy one or more of the objectives listed above.

2. Only experienced personnel under the supervision of the appropriate conservation authority should be allowed to capture and translocate animals.

3. Captures should not prejudice the survival of the wild stock unless the danger of extinction is so imminent that relocation or captive breeding are the only means of saving it.

4. No captures for an enclosed breeding unit should be allowed if there is evidence that the species will not breed in captivity.

5. Sufficient animals should be taken to ensure breeding viability.

6. Reintroductions should only be made with ecological advice.

On the methods of capture the statement says that the choice largely depends on the species, but pre-capture surveys of the region are normally essential. Drug immobilisation is not necessarily superior to conventional methods. Aftercare of the animals is the most critical stage in capture operations, and arrangements for pens, food, crates, and acclimatisation enclosures must be made well in advance.

The statement concludes that capture programmes should be planned and implemented as part of an overall rehabilitation project often requiring international co-operation and agreement. They should be submitted to the SSC which will advise on the international implications, try to raise funds if needed, and co-ordinate propagation in captivity and eventual re-introductions into the wild in consultation with national authorities. 